\title{
EFEITO DE TELAS DE SOMBREAMENTO NO CRESCIMENTO E PROTEÇÃO DE MUDAS DE Toona ciliata SOB BAIXAS TEMPERATURAS
}

\author{
Rudinei De Marco ${ }^{1}$, Bruno Conte ${ }^{2}$, Edison Rogério Perrando ${ }^{3}$, Fabiano de Oliveira Fortes ${ }^{3}$, \\ Lucindo Somavilla ${ }^{4}$, Mário Boff Burgin ${ }^{5}$ \\ ${ }^{1}$ Eng. Florestal, Mestrando, UFSM, Frederico Westphalen, RS, Brasil - rudineidemarco@ yahoo.com.br \\ ${ }^{2}$ Eng. Florestal, Mestrando, UFSM, Santa Maria, RS, Brasil - brunoconte89@ hotmail.com \\ ${ }^{3}$ Eng. Florestal, Dr., Depto. de Engenharia Florestal, UFSM, Frederico Westphalen, RS, Brasil - eperran@terra.com.br; \\ fabianofortes@gmail.com \\ ${ }^{4}$ Eng. Agrônomo, Mestrando, UFSM, Frederico Westphalen, RS, Brasil - lucindosomavilla@ hotmail.com \\ ${ }^{5}$ Acadêmico de Eng. Florestal, UFSM, Frederico Westphalen, RS, Brasil - marioboffburgin@ hotmail.com
}

Recebido para publicação: 26/08/2013 - Aceito para publicação: 09/04/2014

\begin{abstract}
O objetivo deste trabalho foi avaliar a influência de diferentes camadas de telas de sombreamento no crescimento e na proteção de mudas de Toona ciliata em períodos de suscetibilidade a geadas. O estudo foi conduzido na Universidade Federal de Santa Maria, Campus Frederico Westphalen, RS. Para a realização do experimento, mudas de Toona ciliata foram mantidas em sacos plásticos com capacidade de três litros e submetidas a quatro tratamentos: mudas sem proteção e mudas sob proteção com camada simples, dupla e tripla de sombreamento. $\mathrm{O}$ delineamento foi o inteiramente casualizado, com quatro repetições de oito mudas por repetição. Foi avaliado o número de mudas com folhas apicais necrosadas, a altura da parte aérea, o diâmetro do colo e a massa seca radicular, aérea e total. Por meio dessas variáveis, foi possível determinar o Índice de Produtividade, o Índice de Qualidade de Dickson e as relações altura/diâmetro e altura/massa seca da parte aérea. A utilização de telas de sombreamento mostrou-se eficiente para a proteção das mudas contra o efeito adverso da geada. $\mathrm{O}$ uso de uma camada simples de sombreamento resultou em maior proteção e consequentemente forneceu as melhores características dendrométricas em relação às demais intensidades de sombreamento.
\end{abstract}

Resumo

Palavras-chave: Tela de proteção; tolerância à geada; cedro australiano.

\begin{abstract}
Effect of shading screens on growth and protection of Toona ciliata seedlings under low temperatures. This research aimed to evaluate the influence of different shading screens layers on the growth and protection of Toona ciliata seedlings in periods of frost susceptibility. The research was conducted on the Santa Maria Federal University, Frederico Westphalen Campus, RS. For the experiment, Toona ciliata seedlings maintained in plastic bags with three liters of capacity each were submitted to four treatments: unprotected seedlings, seedlings under protection with a single shading layer, double and triple. The experimental design was the completely randomized, with four repetitions of eight seedlings each. It was evaluated the number of seedlings with necrosed apical leaves, the aerial part height, the lap diameter and the dry mass of root, aerial and total. By such variables, it was possible to determine the Produtivity Index, the Dickson Quality Index and the relations height/diameter and height/dry mass of aerial part. The use of shading screens showed up efficient to protect the seedlings against the adverse effect of frost. The use of a single layer of shading resulted in a greater protection and consequently provided the best dendrometric characteristics, compared to the others levels of shading.

Keywords: Screen protection; tolerance to frost; Australian cedar.
\end{abstract}

\section{INTRODUÇÃO}

O cedro-australiano (Toona ciliata M. Roem var. australis), pertencente à família Meliaceae, é uma espécie florestal de rápido crescimento e de perceptível adaptação às condições edafoclimáticas brasileiras, especialmente na região Sudeste do país, onde vem sendo cultivada e, paralelamente, 
submetida a pesquisas que a apontam com excelente potencial silvicultural. $T$. ciliata pode ser encontrada naturalmente na Î́ndia e Malásia, até o norte da Austrália. Possui similaridade botânica com o cedro-rosa (Cedrela fissilis Vell.) e o mogno (Swietenia macrophylla King) nativos do Brasil, no entanto a principal vantagem constatada em relação a essas espécies brasileiras é a ausência de ataques pela broca Hypsipyla grandella Zeller, praga que acomete a gema apical de mudas e árvores adultas da família Meliaceae, bifurcando-as (LORENZI et al., 2003; PINHEIRO et al., 2003).

Nos últimos anos, $T$. ciliata vem se destacando no segmento de madeira serrada, sobretudo pelo potencial madeireiro apresentado pela espécie. Murakami (2008) relata consideráveis níveis de produtividade dessa espécie, sendo observado incremento médio anual de 20 a $30 \mathrm{~m}^{3}$.ha ${ }^{-1}$. Diante desse resultado, é de suma importância a aquisição de mudas sadias e vigorosas para o estabelecimento de plantios florestais, sendo este o primeiro passo para a formação de povoamentos com qualidade.

Para Ricken et al. (2011), a temperatura ótima para o desenvolvimento da T. ciliata é de 20 a $26^{\circ} \mathrm{C}$, sendo essa espécie tolerante a baixas temperaturas, mas não a geadas, principalmente na fase juvenil. Contudo, Murakami (2008) comenta que a espécie sobrevive a temperaturas mínimas absolutas pouco abaixo de $0{ }^{\circ} \mathrm{C}$, podendo tolerar geadas leves e de curta duração.

Na região Sul do Brasil, a produção de mudas de diversas espécies florestais é limitada durante o inverno, em virtude da ocorrência de baixas temperaturas, que favorecem a formação de geadas. Considerando que as plantas são mais suscetíveis às intempéries ambientais na fase inicial do seu desenvolvimento, se faz necessário a tomada de medidas para a proteção das mudas em viveiros instalados nessas regiões. De acordo com Caramori et al. (2000), a proteção contra a geada nos canteiros ou sementeiras no viveiro pode ser realizada pelo uso de cobertura com materiais vegetais, plásticos, malhas aluminizadas ou telas de sombreamento. Teltela et al. (1995) afirmam que as telas de sombreamento são efetivas para reduzir danos causados pelas geadas, pois bloqueiam a radiação de ondas longas durante o período da noite e, por consequência, mantêm a temperatura das mudas mais elevadas que as do ambiente externo.

Estudos sobre o uso de telas de sombreamentos para proteção de mudas de espécies florestais contra danos causados pelas baixas temperaturas são ainda escassos, especialmente para a T. ciliata, visto ser recente a aceitação dessa espécie pelo setor florestal. Nesse contexto, o objetivo do presente trabalho foi avaliar diferentes camadas de telas de sombreamento no crescimento e na proteção de mudas de $T$. ciliata nos períodos de suscetibilidade a geadas.

\section{MATERIAL E MÉTODOS}

O estudo foi realizado no Viveiro Florestal da Universidade Federal de Santa Maria, Campus Frederico Westphalen, RS. O Campus localiza-se na região norte do estado do Rio Grande do Sul, conhecida como região do Alto Uruguai, a uma altitude média de $465 \mathrm{~m}$, com latitudes de $27^{\circ} 23^{\prime} 47^{\prime}$ ' sul e longitude de $53^{\circ} 25^{\prime} 41^{\prime \prime}$ oeste. Segundo a classificação de Köppen, o clima é do tipo Cfa, com precipitação anual variando de 1.900 a $2.200 \mathrm{~mm}$ (ALVARES et al., 2013).

O estudo foi conduzido por seis meses (março a setembro de 2011). Nesse período ocorreram sete geadas, sendo a mais severa registrada no dia 28 de junho, atingindo temperatura mínima absoluta de $-2,6{ }^{\circ} \mathrm{C}$, segundo dados obtidos da estação meteorológica automática do Instituto Nacional de Meteorologia (INMET), vinculado ao Laboratório de Agroclimatologia do Campus Frederico Westphalen, RS, distante a 200 metros do experimento. A figura 1 representa as temperaturas mínimas absolutas registradas no período de 15 de junho a 14 de agosto, meses de ocorrência das sete geadas.

O experimento foi conduzido em delineamento inteiramente casualizado com quatro tratamentos e quatro repetições de oito mudas cada, totalizando 128 mudas. Os tratamentos foram: mudas sem proteção, mudas com cobertura simples (uma tela de sombreamento 50\%), mudas com dupla cobertura (duas telas de sombreamento 50\% sobrepostas) e mudas com tripla cobertura (três telas de sombreamento $50 \%$ sobrepostas). As mudas utilizadas foram originadas de sementes provenientes do Laboratório de Silvicultura da Sociedade de Investigações Florestais (SIF), em Viçosa, MG, as quais foram mantidas em casa de vegetação e germinadas em sementeiras. Cerca de 200 plântulas (altura média de cinco centímetros) foram transplantadas para sacos plásticos com capacidade de três litros. Após o transplante, as mudas permaneceram em casa de vegetação por mais 30 dias antes de serem alocadas ao propósito do estudo, sendo selecionadas as 128 mudas com maior uniformidade em altura e diâmetro do colo. 


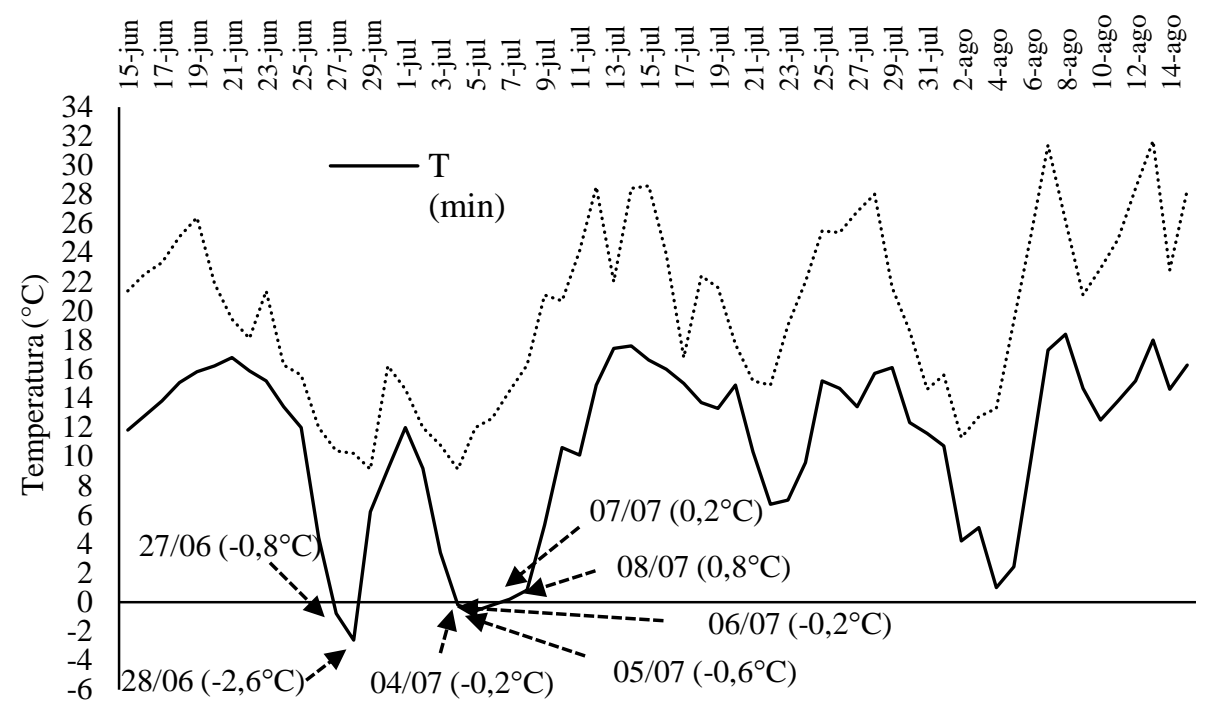

Figura 1. Temperaturas máximas e mínimas absolutas nos sete dias de ocorrência das geadas no local de condução do estudo, no período de 15 de junho a 14 de agosto de 2011. Linha pontilhada: temperatura máxima; linha contínua: temperatura mínima; setas representam as datas de ocorrência das geadas e entre parênteses a respectiva temperatura mínima absoluta.

Figure 1. Absolute minimum and maximum temperatures in the seven days of the occurrence of frosts in the focused place from June 15 to August 14, 2011 (dotted line: maximum temperature, continuous line: minimum temperature, arrows represent the dates of frosts occurrence and among parenthesis the respective absolute minimum temperature).

As telas de sombreamento foram instaladas sobre as mudas a uma altura de 1,30 metros do nível do solo. A distribuição das mudas, em cada tratamento, foi no espaçamento de $40 \mathrm{~cm}$ entre si, tanto na linha como na entrelinha, sendo que na ocasião da implantação foi mensurada a altura total $(\mathrm{cm})$ e o diâmetro do colo $(\mathrm{mm})$ das mudas, como caracterização inicial de avaliação, a partir da qual foi possível avaliar o incremento das variáveis. No decorrer do estudo, as irrigações foram realizadas manualmente, de acordo com as condições meteorológicas, possibilitando a manutenção adequada da umidade no substrato para o desenvolvimento das mudas.

Com auxílio de um luxímetro digital, foi mensurado o fluxo luminoso incidente na área de estabelecimento das mudas (próximo ao meristema apical), para determinação da iluminância proporcionada pelas diferentes coberturas (Tabela 1). Esse procedimento foi na forma de amostragem, com mensuração da iluminância durante os sete primeiros dias de cada mês, medindo-se em dias com chuva, dias nublados e dias ensolarados. A medição foi realizada em três horários durante o dia (09h00min; 12h00min e $15 \mathrm{~h} 00 \mathrm{~min})$. Para caracterizar a transparência proporcionada pelas diferentes coberturas, foi utilizada a média das avaliações ao final do estudo.

Após a ocorrência de cada geada, avaliaram-se os danos diretos causados sobre as mudas sob cada cobertura (tratamento), contabilizando-se as mudas que apresentaram folhas apicais necrosadas (FAN). Para análise estatística dessa variável, foi utilizado o somatório da variável resposta FAN de cada muda após a ocorrência das sete geadas, sendo contabilizado o valor proporcional unitário devido ao diferente número de folhas por muda. Ao término do experimento (180 dias após a instalação), foram mensuradas as seguintes variáveis: altura total $(\mathrm{H})$ e diâmetro do colo (DC), com o auxílio de uma régua graduada e paquímetro digital, respectivamente; massa seca da parte radicular (MSPR) e da parte aérea (MSPA). O sistema radicular foi submetido a lavagem em água corrente para retirada do substrato. Para a secagem, as raízes e a parte aérea das mudas foram mantidas em estufa de circulação forçada de ar a $70{ }^{\circ} \mathrm{C}$, até atingirem peso constante. Para determinação da massa seca, utilizou-se balança digital com precisão de duas casas decimais. A massa seca total (MST) foi determinada pela soma da MSPR à MSPA. Em seguida, utilizando os valores finais e iniciais da $\mathrm{H} \mathrm{e} \mathrm{DC}$, determinou-se o Índice de Produtividade (IP), utilizando-se a fórmula IP $\left(\mathrm{cm}^{3}\right)=\left[(\mathrm{Hf}-\mathrm{Hi}) *(\mathrm{DCf}-\mathrm{DCi})^{2} / 1000\right]$, proposta por Cantarelli et al. (2004). 
Com o intuito de avaliar a qualidade das mudas, foram quantificados a relação da altura com o diâmetro do colo (H/DC), a altura e massa seca da parte aérea (H/MSPA) e o Índice de Qualidade de Dickson (IQD), proposto por Dickson (1960) pela fórmula IQD = [MST/(H/DC+MSPA/MSPR)].

Os dados obtidos neste estudo foram submetidos às pressuposições do modelo matemático e posteriormente à análise de variância pelo teste $\mathrm{F}$, e as médias comparadas pelo teste de Duncan a 5\% de probabilidade, por meio do programa estatístico SAS (2002).

\section{RESULTADOS E DISCUSSÃO}

Na tabela 1 é possível verificar a redução dos valores médios do fluxo luminoso com o acréscimo das camadas de tela de sombreamento. Entre o tratamento sem tela de proteção (pleno sol) e uma camada simples, houve redução de 46,46 klx.m ${ }^{-2}(63,7 \%)$, diferindo significativamente entre esses tratamentos. Com a utilização de camada tripla, foi constatada a menor iluminância, com apenas $3,59 \mathrm{klx} . \mathrm{m}^{-2}$, não diferindo significativamente com o tratamento com camada dupla $\left(10,70 \mathrm{klx} . \mathrm{m}^{-2}\right)$.

Tabela 1. Valores médios de iluminância (E) obtidos embaixo das diferentes camadas de tela de sombreamento das mudas, Frederico Westphalen, RS, 2011.

Table 1. Average values of illuminance (E) of the seedling obtained under the different layers of shading screens, Frederico Westphalen, RS, 2011.

\begin{tabular}{lcccc}
\hline Tratamentos & Sem proteção & Camada simples & Camada dupla & Camada tripla \\
\hline klx.m ${ }^{-2}$ & $72,95 \mathrm{a}^{*}$ & $26,49 \mathrm{~b}$ & $10,70 \mathrm{c}$ & $3,59 \mathrm{c}$ \\
Erro padrão & 5,67 & 2,04 & 0,99 & 0,25 \\
\hline
\end{tabular}

* Médias seguidas pela mesma letra não diferem estatisticamente entre si pelo teste de Duncan ao nível de $5 \%$ de probabilidade.

A análise da variância indicou que as diferentes camadas de telas de sombreamento exerceram influência sobre as variáveis estudadas, exceto para a relação H/MSPA, na qual não foi observada diferença significativa entre as médias dos tratamentos ao final dos 180 dias de implantação do experimento (Tabela 2).

Tabela 2. Resumo da análise de variância para as variáveis das mudas avaliadas no estudo, Frederico Westphalen, RS, 2011.

Table 2. Resume of the analisys of variance for the variables of the seedlings evaluated on the research, Frederico Westphalen, RS, 2011.

\begin{tabular}{lccc}
\hline Variáveis & F & CV $(\%)$ & Resíduo \\
\hline DC $(\mathrm{mm})$ & $5,66^{*}$ & 12,31 & 0,45 \\
H $(\mathrm{cm})$ & $39,22^{*}$ & 11,42 & 3,07 \\
IP $\left(\mathrm{cm}^{3}\right)$ & $10,63^{*}$ & 29,45 & 0,02 \\
MSPA $(\mathrm{g})$ & $11,12^{*}$ & 21,02 & 13,91 \\
MSPR $(\mathrm{g})$ & $5,31^{*}$ & 28,88 & 20,32 \\
MST $(\mathrm{g})$ & $11,79^{*}$ & 19,81 & 43,67 \\
Mudas com FAN $(\%)$ & $17,62^{*}$ & 27,41 & 231,12 \\
H/DC & $27,63^{*}$ & 11,86 & 0,11 \\
H/MSPA & $1,88^{\text {ns }}$ & 18,75 & 0,03 \\
IQD & $5,76^{*}$ & 23,92 & 4,14 \\
\hline
\end{tabular}

DC: diâmetro do colo; H: altura; IP: índice de produtividade; MSPA: massa seca parte aérea; MSPR: massa seca parte raiz; MST: massa seca total; FAN: folhas apicais necrosadas; H/DC: razão altura/diâmetro do colo; IQD: Índice de Qualidade de Dickson; F: estatística do teste F; CV: coeficiente de variação; * significativo ao nível de $5 \%$ de probabilidade $(0,01 \leq \mathrm{p} \leq 0,05)$; ${ }^{n}$ não significativo $(\mathrm{p}>0,05)$.

Entre as variáveis analisadas, observa-se que todas as coberturas com telas de sombreamento beneficiaram as mudas contra a ação direta da geada, proporcionando maior desenvolvimento das mudas, quando comparadas com as mudas expostas sem proteção (Figura 2). $\mathrm{O}$ uso de uma camada simples de tela de sombreamento apresentou maior incremento em DC, embora este não tenha diferido significativamente do tratamento com uso de camada dupla de tela de sombreamento (Figura 2A). Campos e Uchida (2002), testando os níveis $0,30 \%, 50 \%$ e $70 \%$ de sombreamento, não verificaram diferenças significativas entre os tratamentos para o jacarandá (Jacaranda copaia (Aubl.) D. Don.). Já em 
estudo de sombreamento para o pau-de-balsa (Ochroma lagopus Swartz), foi verificado maior crescimento em diâmetro do colo quando utilizado nível de 30\% de sombra (SCALON et al., 2003). De acordo com Scalon et al. (2003), os diferentes graus de luminosidade podem causar mudanças morfológicas e fisiológicas na planta, podendo ser diferente entre as espécies vegetais em função das características particulares de cada espécie.

Com relação ao incremento em altura das mudas, os tratamentos com camada dupla e tripla de tela de sombreamento foram superiores aos demais tratamentos (Figura 2B). O maior incremento em altura desses tratamentos pode ser explicado pela redução de luz, que ocasionou estiolamento das mudas. Resultado similar foi encontrado por Engel e Poggiani (1990) em estudos com o ipê-felpudo (Zeyhera tuberculosa (Vell.) Bur.), em que constataram uma tendência de estiolamento das mudas quando condicionadas a níveis elevados de sombreamento. Rosa et al. (2009) também mencionam que o paricá (Schizolobium amazonicum Huber ex Ducke) teve maior crescimento em altura com a elevação do nível de sombreamento, resposta essa atribuída à deficiência de radiação solar.

Com a restrição de luz, as auxinas promovem a aceleração do crescimento da parte aérea. Esse hormônio é sintetizado, basicamente, em folhas jovens da parte aérea e no ápice do caule, sendo, posteriormente, transportado de modo basípeto aos tecidos subjacentes. Quando ocorre deficiência luminosa, a auxina é redistribuída para a epiderme e células corticais do hipocótilo, ocasionando o alongamento desses tecidos e, portanto, o estiolamento da muda (MORELLI; RUBERTI, 2000; TAIZ; ZEIGER, 2013). No entanto, percebe-se que o tratamento com tripla camada de tela de sombreamento, cujo intuito seria fornecer maior nível de proteção às mudas em geada, acabou por prejudicá-las no incremento vegetativo, embora não apresentando diferença estatística significativa com o tratamento com camada dupla de tela de sombreamento. Provavelmente, a redução de luminosidade no tratamento com tripla camada de tela de sombreamento (em média $3,59 \mathrm{klx} . \mathrm{m}^{-2}$ ) pode ter reduzido a taxa fotossintética, acarretando menor incremento em $\mathrm{H}$ quando comparado ao tratamento com camada dupla $\left(10,70 \mathrm{klx} . \mathrm{m}^{-2}\right.$ de luminosidade), embora não tenha ocorrido diferença estatística entre esses dois tratamentos (Tabela 1). Rosa et al. (2009) relatam que o aumento no crescimento em altura de mudas de paricá foi acompanhado pela redução da sua taxa de crescimento diamétrico, corroborando os resultados observados nas figuras $2 \mathrm{~A}$ e $2 \mathrm{~B}$ para os tratamentos com camada simples e dupla de tela de sombreamento.

Quanto ao IP das mudas, não foi encontrada diferença entre os tratamentos que receberam cobertura (Figura 2C). No entanto, o tratamento sem proteção apresentou resultados significativamente inferiores aos demais tratamentos. Como o IP é dependente da $\mathrm{H}$ e do DC das mudas, sendo o segundo quadrático, o seu resultado acompanhou os verificados para a variável DC, em que a magnitude das duas maiores médias das variáveis DC e IP foi observada nos tratamentos com camadas simples e duplas de sombreamento.

Para as variáveis MSPA, MSPR e MST (Figuras 2D, 2E e 2F), as maiores médias foram obtidas quando utilizada camada simples de sombreamento, seguidas pelos tratamentos com camadas duplas e triplas, que não apresentam diferença significativa entre si. Da mesma forma que o incremento em DC, com a elevação do número de camadas de tela de sombreamento e, consequentemente, do nível de sombreamento, houve decréscimo da massa seca a partir da utilização de duas camadas. A influência do sombreamento sobre a produção de massa seca também foi constatada para outras espécies de porte arbóreo, tais como angelim-vermelho (Dinizia excelsa Ducke), cupiuba (Goupia glabra Aublet), paricá (Schizolobium amazonicum Huber ex Ducke) e eucalipto (Eucalyptus grandis Hill ex Maiden) (VARELA; SANTOS, 1992; DANIEL et al., 1994; ROSA et al., 2009; SANTOS et al., 2010), nas quais foi observada maior produção de massa seca em níveis de sombreamento próximos a $30 \%$.

A avaliação da resistência das mudas de $T$. ciliata por injúrias causadas pela geada, expressas em porcentagens de mudas com folhas apicais necrosadas (Figura $2 \mathrm{G}$ ), mostrou resultados superiores nas mudas estabelecidas em pleno sol, cuja FAN foi de 100\%. Com o uso de apenas uma tela de sombreamento, foram alcançadas as menores porcentagens de mudas necrosadas pela geada $(25 \%)$, diferindo significativamente dos tratamentos sem proteção e com dupla tela de sombreamento. No entanto, o tratamento utilizando três camadas de tela de sombreamento não diferiu do tratamento com o uso de uma camada simples. Porém, no tratamento com três telas de sombreamento, contatou-se aumento de $18,75 \%$ na quantidade de mudas com a região apical necrosada pela geada. Pode-se inferir que a redução de eficiência na proteção à geada quando utilizada mais de uma camada de tela se deve, provavelmente, ao fato de as mudas apresentarem-se mais tenras com o aumento do sombreamento e, consequentemente, os tecidos vegetativos se tornarem mais susceptíveis a determinadas intempéries climáticas, seja pela ocorrência de geadas, seja por temperaturas muito próximas ao ponto de 
congelamento da água. A geada prejudicou diretamente as mudas, sendo a modificação da cor das folhas (coloração escura) e abscisão das mesmas o sintoma mais evidente. No entanto, é importante ressalvar que, à medida em que houve a elevação das temperaturas, as mudas rebrotaram, retomando o crescimento vegetativo.

Quando comparadas com os demais tratamentos, percebe-se que as variáveis DC, MSPA, MSPR e MST foram maiores no tratamento com apenas uma camada de tela de sombreamento (Figura 2). Possivelmente as maiores médias observadas para essas variáveis estejam associadas à menor influência das geadas ocorridas (Figura 2G), possibilitando a permanência das folhas e, consequentemente, o maior crescimento das mudas, embora os níveis de sombreamento possam ser caracterizados como fatores que modificam o padrão de crescimento das mudas.
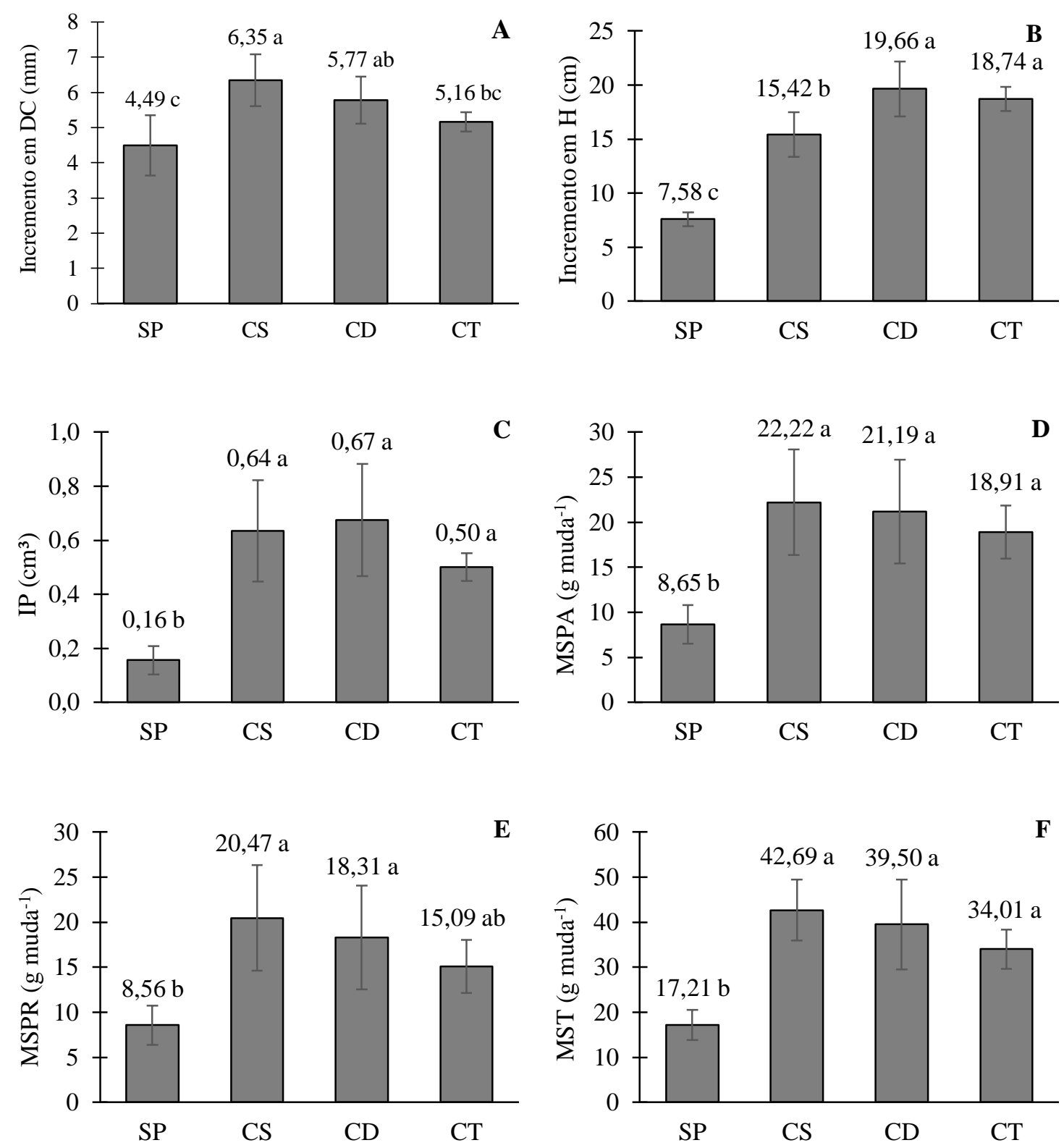


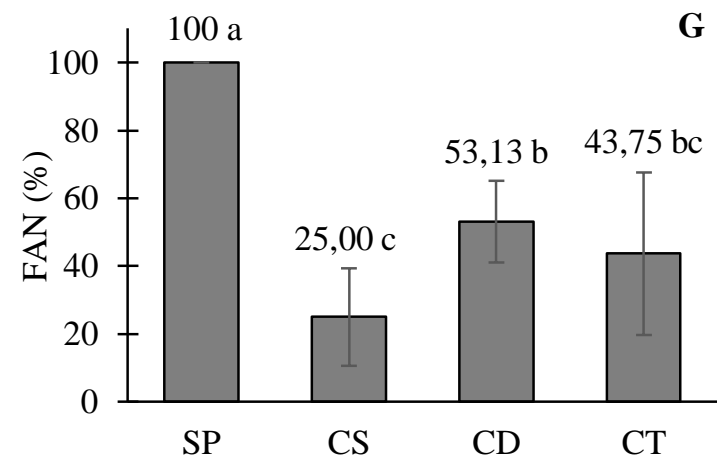

Figura 2. Comparação de médias para a variável incremento em DC: diâmetro do colo (A), H: altura total (B), IP: índice de produtividade (C), MSPA: massa seca parte aérea (D), MSPR: parte raiz (E) e MST: total (F), FAN: mudas com folhas apicais necrosadas (G), para as diferentes camadas de tela de sombreamento: SP: sem proteção, CS: camada simples, CD: camada dupla e CT: camada tripla. Médias seguidas pela mesma letra não diferem estatisticamente entre si pelo teste de Duncan, ao nível de 5\% de probabilidade.

Figure 2. Comparison of averages to increment variable in DC: lap diameter (A), H: total height (B), PI: productivity index (C) MSPA: shoot dry mass (D), MSPR: root of (E ) and MST: Total (F), FAN: seedlings with necrosed apical leaves (L), for the different layers of shade cloth: SP: unprotected, CS: simple layer, CD: double layer and CT: triple layer. Averages followed by the same letter do not differ significantly by the Duncan test at 5\% probability.

A análise da relação existente entre as variáveis H/DC, H/MSPA e IQD serviram de base para o estabelecimento de critérios que definissem a qualidade das mudas expostas sob as diferentes camadas de telas de sombreamento (Figura 3). De acordo com Carneiro (1995), o valor resultante entre a divisão da H e o DC exprime o equilíbrio de crescimento, relacionando essas duas importantes variáveis morfológicas em apenas um índice. Denominado também de quociente de robustez, é considerado por Johnson e Cline (1991) um dos índices mais precisos, pois fornece informações de quanto delgada está a muda. Para Carneiro (1995), as mudas devem apresentar diâmetros de colos maiores para um melhor equilíbrio do crescimento da parte aérea. Scremin-Dias et al. (2006) afirmam que o diâmetro do colo espesso indica que a muda apresenta aspecto sadio e está apta para o plantio a campo. Neste estudo, percebe-se que a menor relação H/DC foi encontrada nas mudas sem proteção, diferenciando-se significativamente dos demais tratamentos. No entanto, é importante ressaltar que as mudas expostas sem cobertura foram $100 \%$ necrosadas pela geada (Figura $2 \mathrm{G}$ ) e, em virtude disso, sofreram influência negativa no incremento em altura e, consequentemente, apresentaram menor relação H/DC (Figura 3A). Fonseca et al. (2002) afirmam que as relações que expressam a qualidade das mudas não devem ser utilizadas isoladamente, chamando a atenção para a possibilidade de ocorrer equívoco se escolhidos apenas esses índices para análise do padrão de qualidade.

Embora sem diferença significativa para a relação H/MSPA (Figura 3B), a menor magnitude foi encontrada quando utilizada apenas uma camada de tela de sombreamento. Para Gomes (2001), quanto menor o quociente obtido pela divisão da altura pelo peso de matéria seca da parte aérea, mais rustificada será a muda e maior deverá ser sua sobrevivência no campo.

Quanto ao IQD, o melhor índice foi alcançado quando utilizada uma camada simples de proteção (Figura 3C). Segundo Fonseca (2000), o IQD é um dos melhores indicadores de qualidade das mudas, pois no cálculo são considerados a robustez e o equilíbrio da distribuição da fitomassa. Quanto a esse índice, Gomes (2001) afirma que quanto maior seu valor, melhor é a qualidade das mudas. 

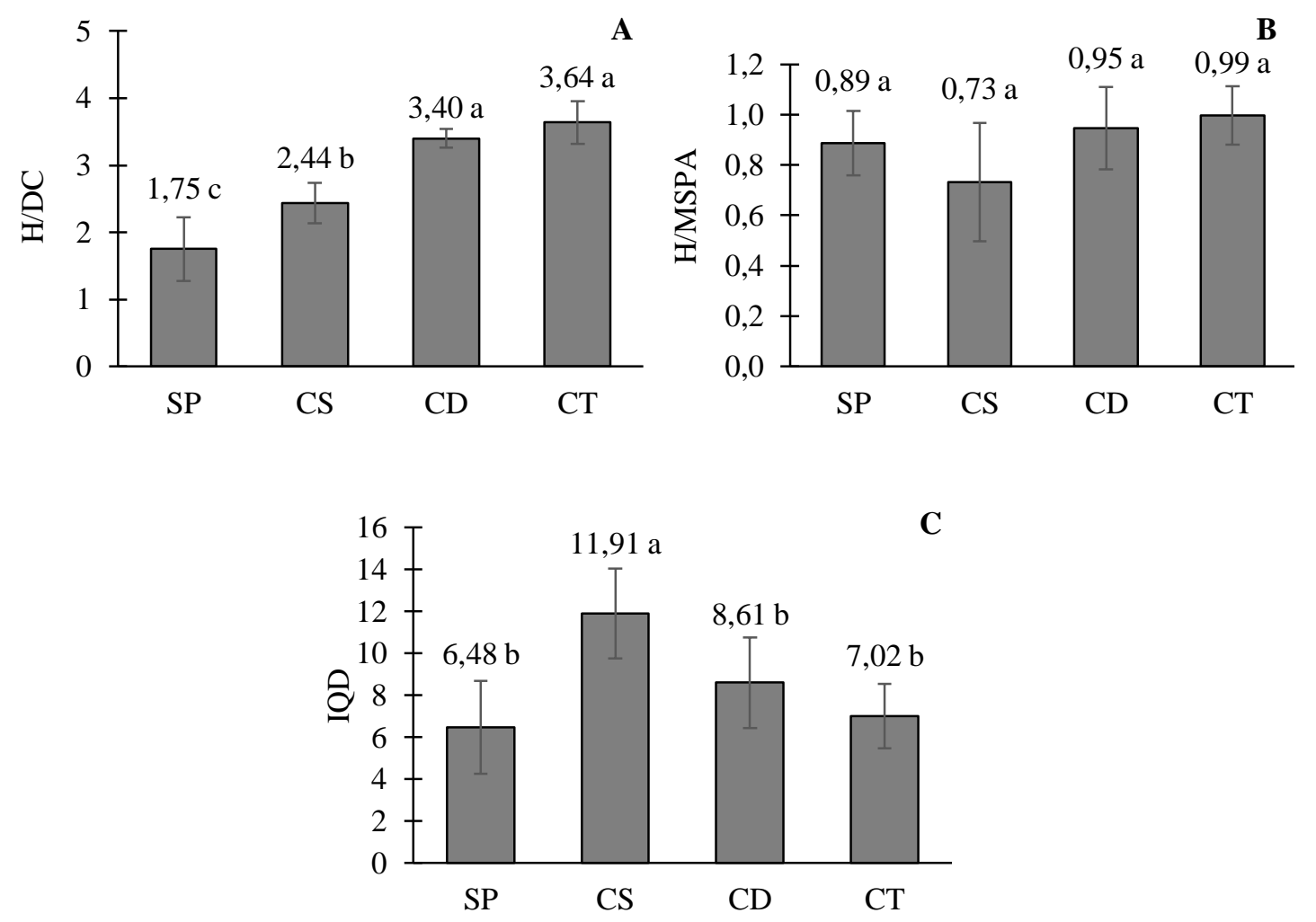

Figura 3. Comparação de médias para os índices de qualidade com base nas relações: H/DC: altura e diâmetro do colo (A), H/MSPA: altura e massa seca parte aérea (B) e IQD: Índice de Qualidade de Dickson (C) para as diferentes camadas de proteção das mudas: SP: sem proteção, CS: camada simples, CD: camada dupla e CT: camada tripla. Médias seguidas pela mesma letra não diferem estatisticamente entre si pelo teste de Duncan, ao nível de 5\% de probabilidade.

Figure 3. Comparison of averages for the quality scores based on the relations: H / DC: height and lap diameter (A), H / MSPA: height and aerial part dry mass (B), and IQD: Dickson Quality Index (C) for the different layers of protection of the seedlings: SP: unprotected, CS: single layer, CD: double layer and CT: triple layer. Averages followed by the same letter do not differ significantly by the Duncan test at $5 \%$ probability.

\section{CONCLUSÕES}

- Nas condições de realização deste estudo, o uso de tela de sombreamento é uma alternativa eficiente na proteção de mudas de T. ciliata quando em condições de susceptibilidade a geadas.

- O uso de uma camada simples de tela de sombreamento proporcionou maior proteção aos efeitos da geada, além de melhorias no padrão de crescimento e de qualidade das mudas.

\section{REFERÊNCIAS}

ALVARES, C. A.; STAPE, J. L.; SENTElHAS, P. C.; GONÇAlVES, J. L. M.; SPAROVEK, G. Köppen's climate classification map for Brazil. Meteorologische Zeitschrift, v. ahead of print, p. 1 - 18, 2013.

CAMPOS, M. A. A.; UCHIDA, T. Influência do sombreamento no crescimento de mudas de três espécies amazônicas. Pesquisa Agropecuária. Brasília, v. 37, n. 3, p. 281 - 288, 2002. 
CANTARELLI, E. B.; ZANON, M. L. B.; DAL'COL LUCIO, A. Índice de produtividade (IP), outra variável observada na pesquisa florestal. In: SIMPÓSIO BRASILEIRO DE PÓS-GRADUACÃO EM ENGENHARIA FLORESTAL, 2004, Manaus. Anais do... Manaus: INPA, 2004. p. 273 - 274.

CARAMORI, P. H.; ANDROCIOLI-FILHO, A.; CARNEIRO-FILHO, F.; OLIVEIRA, D.; MORAIS, H.; LEAL, A. C.; GALDINO, J. Métodos de proteção contra geadas em cafezais em formação. Londrina: IAPAR, 2000. (Informe da Pesquisa). Disponível em:<http://www.iapar.br/arquivos/File/zip_ pdf/protgeada.pdf>. Acesso em: 19/03/2013.

CARNEIRO, J. G. A. Produção e controle de qualidade de mudas florestais. Curitiba: UFPR/FUPEF, Campos: UENF, 1995. $451 \mathrm{p}$.

DANIEL, O.; OHASHI, S. T.; SANTOS, R. A. Produção de mudas de Goupia glabra (cupiúba): Efeito de níveis de sombreamento e tamanho de embalagens. Revista Árvore, Viçosa, v. 18, n. 1, p. 1 - 13, 1994.

DICKSON, A.; LEAF, A. L.; HOSNER, J. F. Quality appraisal of white spruce and white pine seedling stock in nurseries. Forest Chronicle, Ontário, v. 36, p. 10 - 13, 1960.

ENGEL, V. L.; POGGIANI, F. Influência do sombreamento sobre o crescimento de mudas de algumas essências nativas e suas implicações ecológicas e silviculturais. Instituto de Pesquisas e Estudos Florestais, Piracicaba, n. 43/44, p. 1 - 10, 1990.

FONSECA, E. P. Padrão de qualidade de mudas de Trema micrantha (L.) Blume, Cedrela fissilis Veli. e Aspidosperma polyneuron Müll Arg. produzidas sob diferentes períodos de sombreamento. $113 \mathrm{f}$. Tese (Doutorado) - Universidade Estadual Paulista, Jabotical, 2000.

FONSECA, E. P.; VALÉRI, S. V.; MIGLIORANZA, E.; FONSECA, N. A. N.; COUTO, L. Padrão de qualidade de mudas de Trema micrantha (L.) Blume, produzidas sob diferentes períodos de sombreamento. Revista Árvore, Viçosa, v. 26, n. 4, p. 515 - 523, 2002.

GOMES, J. M. Parâmetros morfológicos na avaliação da qualidade de mudas de Eucalyptus grandis, produzidas em diferentes tamanhos de tubete e de dosagens de N-P-K. $166 \mathrm{f}$. Tese (Doutorado em Ciência Florestal) - Universidade Federal de Viçosa, Viçosa, 2001.

JOHNSON, J. D.; CLINE, P. M. Seedling quality of southern pines. In: DUREYA, M. L.; DOUGHERTY, P. M. (Eds.). Forest regeneration manual. Dordrecht: Kluwer Academic Publishers, 1991. p. 143 - 162.

LORENZI, H.; SOUZA, H. M. de; TORRES, M. A. V.; BACHER, L. B. Árvores exóticas no Brasil: madeireiras, ornamentais e aromáticas. Nova Odessa: Instituto Plantarum, 2003. 368 p.

MORELLI, G.; RUBERTI, I. Shade avoidance responses. Driving auxin along lateral routes. Plant Physiology, Bethesda, v. 122, p. 621 - 626, 2000.

MURAKAMI, C. H. G. Cedro-australiano: valorização de espécies nobres. Boletim Florestal Informativo Florestal do Norte Pioneiro. 7. ed. p. 1 - 4, 2008.

PINHEIRO, A. L.; LANI, L. L.; COUTO, L. Cultura do cedro-australiano para produção de madeira serrada. Viçosa, MG: Universidade Federal de Viçosa, 2003, 42 p.

RICKEN, P.; MATTOS, P. P.; BRAZ, E. M.; KALIL FILHO, A. N. Crescimento diamétrico de povoamento de Toona ciliata var. australis em Adrianópolis, PR. Comunicado Técnico. Colombo, p. 1 4, 2011.

ROSA, L. S.; VIEIRA, T. A.; SANTOS, D. S.; SILVA, L. C. B. Emergência, crescimento e padrão de qualidade de mudas de Schizolobium amazonicum Huber ex Ducke sob diferentes níveis de sombreamento e profundidades de semeadura. Revista Ciência Agrária, p. 87 - 98, 2009.

SANTOS, R. F.; MORAIS, L.; BORSOI, A.; SECCO, D.; MOREIRA, G. C. Níveis de sombreamento na produção e desenvolvimento de mudas Eucalyptus grandis Hill ex Maiden. Pesquisa Aplicada e Agrotecnologia. v. 3, n. 3, Set.-Dez. 2010. (Online) e-ISSN 1984 - 7548. Disponível em: $<$ http://revistas.unicentro.br/index.php/repaa/article/view/1154/1254>. Acesso em: 08/09/2012. 
SAS LEARNING EDITON. Getting Started with the SAS Learning Edition. Cary: SAS Institute. 2002. $81 \mathrm{p}$.

SCALON, S. P. Q.; MUSSURY, R. M.; RIGONI, M. R.; SCALON FILHO, H. Crescimento inicial de mudas de Bombacopsis glabra (Pasq.) A. Robyns sob condições de sombreamento. Revista Árvore, Viçosa, v. 27, n. 6, p. 753 - 758, 2003.

SCREMIN-DIAS, E.; KALIFE, C.; MENEGUCCI, Z. R. H.; SOUZA, P. R. Manual de Produção de mudas de espécies florestais nativas. Campo Grande, 2006. 57 p.

TAIZ, L.; ZEIGER, E. Auxina: o primeiro hormônio do crescimento vegetal descoberto. In: TAIZ, L.; ZEIGER, E. Fisiologia vegetal. 5. ed. Porto Alegre, 2013. p. 543 - 580.

TELTELA, M.; PELPERA, U. M.; ZVIELLO, Y. Telas de sombreamento como proteção contra geadas. Instituto de Engenharia Agrícola, Org. de Investigação Agrícola, Centro, Volcani, P. O. Box 6, MBet Dágan, Israel. 1995. Disponível em: <http://www.polysack.com/files/7b1c12dbf7d018e35b8589 d4f9597069.pdf>. Acesso em: 10/07/2013.

VARELA, V. P.; SANTOS, J. Influência do sombreamento na produção de mudas de angelim-pedra (Dinizia excelsa Ducke). Acta Amazônica, Manaus, v. 22, n. 3, p. 407 - 411, 1992. 